\title{
sciendo
}

Research Article

(C) 2019 Ngamvoratham et.al. This is an open access article licensed under the Creative Commons Attribution-NonCommercial-NoDerivs License (http://creativecommons.org/licenses/by-nc-nd/3.0/).

\section{Interior Environmental Design for a Leisure Learning Area in the National Gallery of Thailand}

\author{
Khorawan Ngamvoratham \\ Ph.D., Candidate in Industrial Education, \\ Faculty of Industrial Education and Technology, \\ King Mongkut's Institute of Technology Ladkrabang (KMITL), Thailand \\ Thanin Ratanaolarn \\ Ph.D., Assistant. Prof., \\ Faculty of Industrial Education and Technology, \\ King Mongkut's Institute of Technology Ladkrabang (KMITL), Thailand \\ Jitjayang Yamabhai \\ Ph.D., Prof., \\ Research Institute for Languages and Cultures of Asia (RILCA), \\ Mahidol University, Thailand

\section{Songwut Aekwutwongsa} \\ Ph.D., Associate. Prof., \\ Faculty of Industrial Education and Technology, \\ King Mongkut's Institute of Technology Ladkrabang (KMITL), Thailand
}

Doi: $10.2478 / \mathrm{mjss}-2019-0027$

\begin{abstract}
The aim of this research study was to design and assess the design of the interior environment for a leisure learning area in the National Gallery of Thailand. The study used a combined quantitative and qualitative methodologies: interviewing the curator, 2 staff members, and the executive director of the National Gallery of Thailand; a physical survey of areas in the gallery; and a questionnaire survey of users' preferences of art activity area. The survey of users' preferences was conducted with a sample group of 600 potential users who were randomly and systematically sampled from a population of firstyear students majoring in applied arts in several governmentally-supported universities in Bangkok. The obtained data on the designs that were based on the concept of functional and aesthetic design and a 'circumplex model of affect' in cognitive theory were analyzed accordingly. The preliminary designs were three arrangement patterns of environmental elements that provided positive stimuli: 1) a pattern for low level of stimuli; 2) one for moderate level; and 3) one for high level of stimuli. These patterns are illustrated in this paper as a layout plan and 3 computer-generated $3 D$ perspectives that were assessed by 10 design experts on a 1-5 Likert rating scale. The means and standard deviations achieved by the 3 patterns indicated that the patterns for medium level and high level of stimuli was of a very high quality with $\bar{X}=4.5, S D=0.14$ and $\bar{X}=4.59, S D=0.19$, respectively. In other words, both patterns were active, functional, aesthetically-pleasing, and proper overall designs for the environmental interior of the intended area in the National Gallery of Thailand.
\end{abstract}

Keywords: Leisure Learning Area, Activity Space, Interior Environment, National Gallery, Environmental Psychology 


\section{Introduction}

Learning outside the classroom enriches students live experience. Teachers always use some museums in their teaching process. Enjoyment in learning can help spark students' imagination. Foley and McPherson (2000) pointed out an art museum should provide recreation to the people. Lin (2013) summarized that art museums should offer entertainment along with learning experience. Setting up a leisure learning program for students in an art museum is a collaborative process between the museum and educational institution (Glesne, 2012).

In Thailand, the National Gallery is an important museum located at the inner Rattanakosin Island, the capital's historic district of Bangkok. This place provides a lot of important traditional and contemporary art collections and presents the evolution of visual art from Sukhothai period to the present. According to the 2017 annual report from the National Gallery of Thailand, there appeared to be fewer number of teachers and students visiting the exhibition there. The National Gallery was aware of this problem and tried to cultivate more learning activities. Therefore, a team of staff from the gallery persuaded teachers from several schools in Bangkok to attend a brainstorming meeting. The conclusion of the meeting was that the museum would add different activities for various groups of students and provoke teachers to make their class more fun by using the art museum as a tool.

Adding enjoyable activities would enhance the leisure educative performance of the National Gallery of Thailand. However, the gallery would need to arrange some of its spaces to support them. What kind of space would make students enjoy an art activity? Certainly, not any general plain space would do; the space had to be designed with this purpose in mind. Therefore, the objectives of this study were to design and assess the design of the interior environment for a leisure learning area in the National Gallery of Thailand. The outcomes would be suitable designs for an art activity area in the museum.

\section{Literature Review}

\subsection{Art Museum in Thailand}

Art museum or art gallery is a type of museums which is a building or a space for exhibition of arts, mostly visual art. The main art gallery of the nation was established by the government as the National Art Gallery of Thailand. The art gallery has a mission to collect object d'art, classify works of arts, register art objects, conduct researches, educate people, organize exhibitions, and provide useful artistic activities for the public (Mukdamanee, 2012).

\subsection{Art Activity and Leisure Learning}

Art museums in the world that provide interesting educational activities are such as the National Art Museum of Singapore and the Newcastle Art Gallery. The museum's activity programs focused on students learning with enjoyment the arts that were exhibited there. Both museums were wellequipped, and their activity areas were well-organized to provide leisure activities (National Gallery Singapore, 2018; Newcastle Art Gallery, 2018).

\subsection{Learning space arrangement}

Organizing a quality-space for a learning activity promotes enjoyable learning. Observed at the 2017's renovation of Seattle's Asian Art Museum, a nice space was added for learning workshops (Testado, 2018). Hardiman (2012) stated that a good physical arrangement was a part of the BrainTargeted Teaching model for enhancing students' creativity. The researcher also suggested that a classroom that were orderly arranged with beautiful artwork decoration would be a powerful instrument for creating lively learning. In addition, a classroom that encouraged cooperative learning promoted positive perceptions of students. (Miller and Cunningham, 2011). 


\subsection{Interior Environmental Design}

Interior environmental design is under the big umbrella of environmental design that considers a larger aesthetic scope (Karavidas, 2017). In an environment, its atmosphere refers to its sensorial qualities. An atmosphere is an immediate form of physical perception, recognized through emotional sensibility (Zumthor, 2006). Rengel (2016) asserted that a good interior environmental design should combine both functionality and aesthetics. Mahmoud (2017) described that visitors' pleasures from the atmosphere can be created by properly arranging the design elements: shapes, textures, colors and lights. Furthermore, Zumthor (2006) explained that different senses from hot or cold temperature, smells of food, sounds of people talking or wind blowing, or even the silence from noise protection inside the room can arouse different feelings as well. Pallasmaa (2014) stated that things in both tangible and intangible environment can be perceived by our six senses.

\subsection{Environmental Psychology}

Augustin \& Coleman (2012) emphasize that paying attention to the psychological evidence of the environment in the design enables designers to understand user's attitudes towards space better, since the design of the space is for the users, not for the designers. Russell (1980) presented a circumplex model that represents all positive and negative human perceptions of the environment. Fig. 1 is our modified circumplex model for a design purpose. It signifies that a certain design of the environment can affect a certain users' emotion. As can be seen in the figure, the circle represents two main sides of emotions, pleasant and unpleasant. A positive stimulation at a moderate scale creates pleasure, but if the stimulation is too small, enthusiasm will be lacking. Conversely, if it is too arousing, it will be distracting. To get good designs, the researcher applied the positive side of this circle to design the environment of the intended area. In addition, the researcher reviewed the literature on the environmental elements that yield positive perceptions and used some of them in this study. They are as followed.

Circular shape: most people responded positively to circular shapes (Wang and Zhang, 2016). It conveys safety, warmth, and happiness (Aronoff et al. 1988, Bar. and Neta, 2006).

Color: The Color Effect Institute reported that blue is the most popular color in the world. Blue is good for communication. Orange provides a positive, warm, and safe feeling (Wright, 2018).

Colour light: Abbas (2006) presented a summary of human's perceptions of color lights. Below are some examples of these. White light is neutral and produces a comfortable feeling. Blue light produces a comfortable feeling as well. Green light is very satisfying and natural light as well. Red light produces an enthusiastic feeling, but it is less favorable than other colors.

Background music: Herrmann (2009) reviewed several studies on the positive effects of using background music in a classroom. The type of background music, its tempo, volume, and duration are important factors in choosing the right music for a specific environment. Moreover, background music also helps people concentrate on their work (Sigman, 2005).

\subsection{Interior Environmental Design Programming}

Palmer (1981) suggested three factors to consider in an interior environmental design: 1) Human Factors-the primarily required relevant information from owner and users, e.g., the owner's objective, the number of users and activities, users' characteristics, perceptions, and comfort; 2) External Factors-those not totally under control but significantly influence the design such as climate, costs, time, or even future conditions; and 3) Physical Factors-things such as the type of space, its dimensions and functions, the types of equipment and furnishings. We considered the above factors attentively in our design programming. Calvin C. Straub, a dominant architect and educator, has stated that, "the program is the Design!" (Hershberger, 1999)

\subsection{Space Quality Assessment}

In order for us to come up with a right design, space quality assessment is necessary. The space 
quality assessment used in this study was based on various papers in the literature, notably a paper by Craik. Craik (1971) is one of the initiators of environmental quality measurement. He pointed out that a thorough assessment of a place should include the following five aspects: measurements of physical and spatial properties, the number and variety of artifacts, the traits of place, the behaviors and activities of users, and the social climate. The assessment on the place's qualities is from the perspective of experts in the corresponding fields. A place can be judged by its photographs, perspective drawings, or models. Diagnosing of a place often involves surveys or rating scale questionnaires, and the results often lead to improved public policy. Craik's approach was well-acknowledged and extended in numerous research studies (Craik and Zube, 1976; Carp and Carp, 1982; Vischer and Fischer, 2005). In our space quality assessment, we adhered to assessing those five aspects mentioned above. In our conceptual framework, the modified wheel of environmental stimuli-related design (Fig. 1) from the original Russell's model [1980] eventually led to assessment outcomes of the five aspects mentioned earlier.

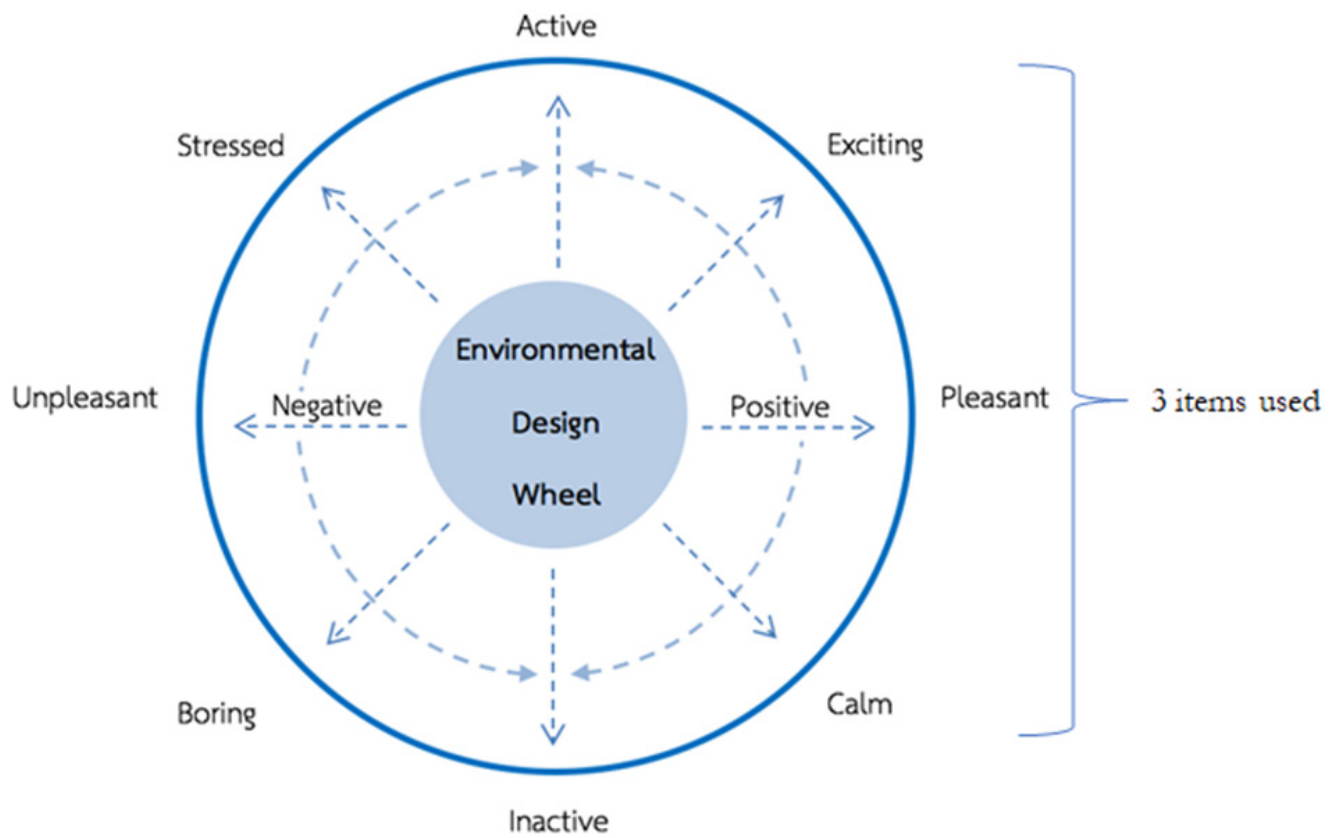

Note: this study used only the 3 indicated items around the wheel.

Figure 1: A view of emotional perceptions as depicted in our modified wheel of environmental stimuli-related design from the original Russell's model (1980)

\subsection{Conceptual Framework}

Our conceptual framework is as shown in Fig. 2. It is based on the concepts, principles, and theories mentioned in the paragraph below.

Our conceptual framework is based on the following: perceptible environmental elements in the atmosphere (space, furniture, equipment, lights, and air) in the idea of Zumthor (2006), Pallasmaa (2014), and Mahmoud (2017); the theory of perceived stimuli in the environment of Russell (1980); positive environmental elements by using various colours and shapes reported by Wright (2018) and Wang \& Zhang (2016); positive feelings evoked by color lights in a study by Abbas (2006); positive feelings evoked by background music in the atmosphere, an idea of Herrmann (2009); human, physical, and external factors derived from the concept of finding evidence for design programming of Palmer (1981); combining all environmental elements 
according to functionality and aesthetics expounded by Rengel (2016); and the concepts of the 5 aspects of a place mentioned above set forth by Craik (1971).

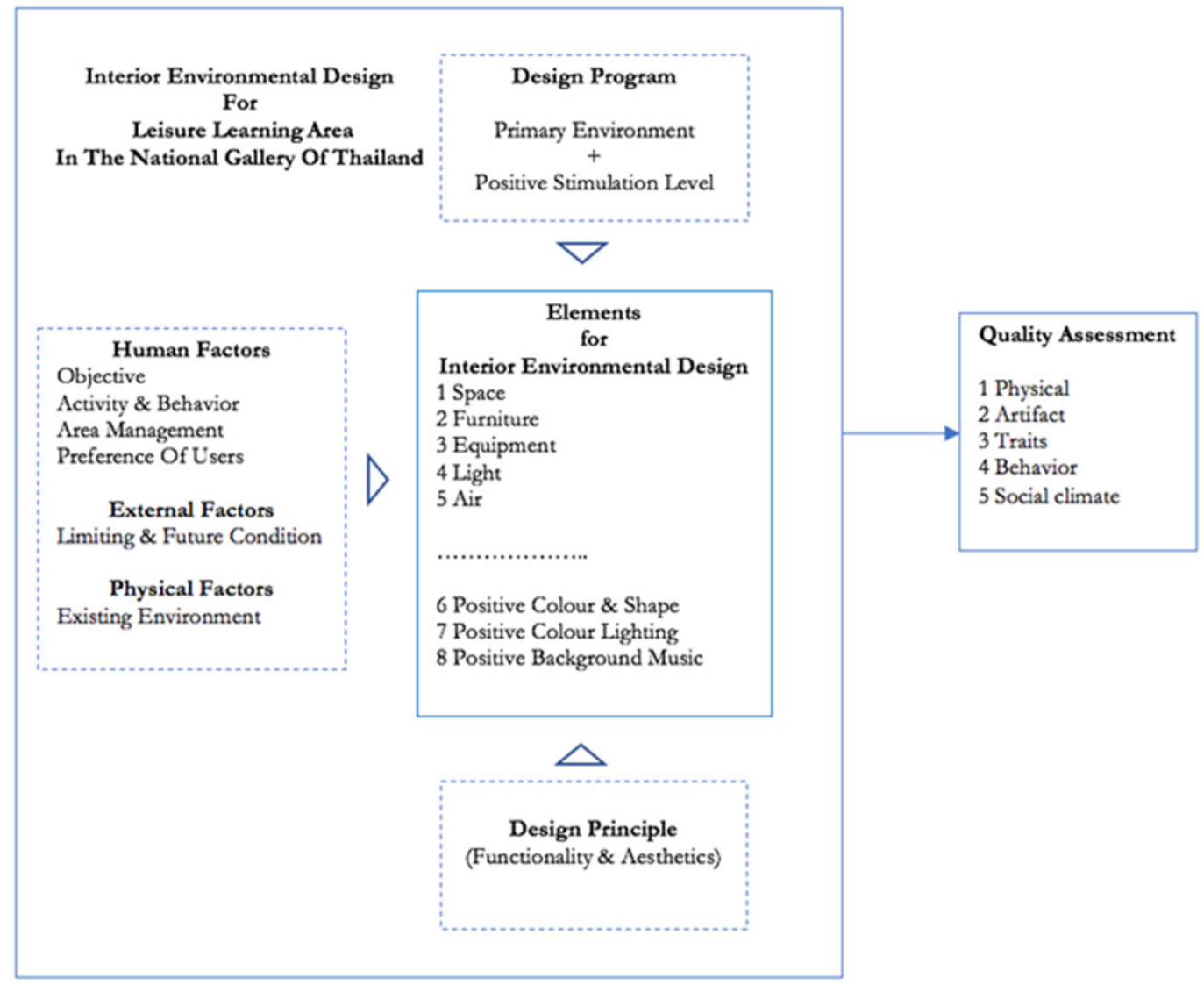

Figure 2: the conceptual framework of this study

\section{Methodology}

The design and development of the interior environment of a leisure learning area in the National Gallery of Thailand was done in 2 steps: design and assessment of the design.

\subsection{Design}

This design step consisted of 2 parts: review of relevant design information and creation of preliminary designs.

The first part involved collecting quantitative and qualitative information relevant to a design and analyzing the acquired information based on our conceptual framework. The details of the data collection method including the tool, the population, and the sample groups are explained below.

The qualitative data collection involved collecting data on human and external factors by recording interviews of four people from the national gallery. The interviewing tool was a semistructured interview form querying about the objectives and the administration of the intended area, its previous users' activities and behaviours, the limitations of the intended area, and the gallery's future plan. The content validity of the form was checked by 5 experts and achieved an index of 
item-objective congruence (IOC) score in the range of $0.67-1.00$. The collected data were analysed and inductively interpreted. The qualitative data collection also involved collecting data on physical factor. A physical survey of the intended area in the national gallery was conducted by using a survey form to record textual descriptions and photographs of it: space, furniture, equipment, lights, air, and decoration. This survey form was also checked by the 5 experts and achieved an IOC score in the range of $0.67-1.00$. The survey results accurately represented the physical environment of the interior.

The quantitative data collection involved human factor data collection. A questionnaire survey was conducted querying the sample group on physical characteristics of the leisure learning area. The sample group consisted of 600 randomly and systematically sampled first-year students majoring in applied arts from several governmentally-supported universities in Bangkok, of which the size of the population was 13,000 students. Regarding the size of samples, Denscombe (2010) provided a table showing that a suitable sample size at $95 \%$ confidence level for a population of 10,000 should be at least 370 . Therefore, we chose the size to be 600 to make sure that it was high enough for our purpose.

The second part was construction of $3 \mathrm{D}$ perspectives of preliminary designs. A layout of the basic environmental elements and positive stimuli were based on the collected data from the first part that were analysed according to widely-accepted interior design principles. The original layout was a basic design. Additional positive stimuli were added to this layout to obtain two more designs with higher and higher degrees of additional stimuli. These three designs were rendered into 3D perspectives with a 3D modeller.

\subsection{Assessment of the designs}

We took the 3 preliminary designs mentioned above to 10 experts to get evaluated. Each of the design included a 3D perspective of the designed area, textual details of the design, and background music. The items in the assessment tool involved evaluation of the quality of the interior environment. The tool was a 1-5 rating Likert scale form which had been checked of its validity and achieved an IOC score in the range of $0.67-1.00$ from other 5 experts. The means and standard deviations of the assessment results from the 10 experts were determined. Then, the designs were judged according to these results.

\section{Research Results}

\subsection{The designs}

\subsubsection{Results pertaining to the pre-design step}

\subsubsection{Qualitative results}

\subsection{Objective for art activity}

One of the targeted results from interviews with 4 people from the National Gallery of Thailand was the leisure learning activity offered by the gallery. We found that the curator had designed an activity named "One Day in the Gallery" as a leisure learning activity for students following one of the objectives of the gallery to provide useful activities to the general public. This activity was part of the strategy for successful implementation of the main mission of the gallery. It was expected that this activity would help develop an effective out-of-class learning method for arts that would be interesting to and enjoyable for the students. Also, it would involve construction of an out-of-class learning area that would act as a prototype for this kind of area in other knowledge sources. The executive director of the gallery told us as below.

"We particularly welcome every student. We would like our surrounding schools and colleges to connect with us more than bring the students around just to quickly watch an exhibition. Our 
gallery is special in the sense that everyone can use it as a learning area. Not everyone outside of the gallery may know about this, so this learning area service has not been sufficiently effective. Only some parents who are familiar with our gallery will encourage their children to visit here and use one of our areas to carry out an art activity in summer. Therefore, we would like to provide a more effective service and connect more closely with educational institutes. This "One Day in the Gallery" activity is likely to become a successful beginning of developments of many more useful learning activities in the future. We wish that teachers and students will come to appreciate our service and use it more than before."

\title{
4.1.1.1.2 Activity procedure and participant behaviour
}

The curator explained that the "One day in the Gallery" activity consisted of two activities: 1) Leisure learning of art objects-the traditional activity that was provided daily; and 2) Leisure learning with poster creation-an extra activity that enhanced the enjoyable experience of the students. The expected number of participants were around 40 students with the teacher, curator, and a curator assistant. The entire activity would start by conducting the first activity for 1 hour then, after a 15-minute break, the second activity for 1 and a half hours. In this activity, the students would be assigned into groups of 5 students. Each group would create a poster inspired by the art objects that they had seen in the first activity. Their expected outcomes were that the students would enjoy the relaxed atmosphere and would be excited and have some fun while doing it. The curator explained the activity as detailed below.

\begin{abstract}
"a simple activity where students are required to cooperate to create an artwork. The goal, creation of a poster, is appropriate to students' artistic skill; the creation time would not be too long, not longer than 2 hours. I would like the students who come here to enjoy the experience and take back with them some knowledge and a good impression which would foster their good attitude towards learning arts. As for the activity, we expect to have the students watching the permanent exhibits for around an hour, taking a 15-minute break, then joining together in groups to do the poster activity. Each group will brainstorm and produce the poster cooperatively as well as present it to the audience. If possible, they will cast votes for the most popular poster so that they will get excited and have some fun. We will also have some special gifts for the winners. At present, we can support 40 students per a round of activity, but will extend this limit further in the future. We need to work closely with the teacher who will have to take care of the students with us because this service is not for leaving the students in our hands but for cooperatively conducting the activity. We will arrange a preliminary activity and work together with the teacher to adapt it to suit the situation, but we do not want this cooperation to be too formal such that it is going to be too stressful. It is important for all of us not to take it too seriously. For the art creation tools such as paints, papers, and brushes, we will provide them ourselves. The students and teacher can come here without any concerns."
\end{abstract}

The outcome of this analysis of participants' activities and behaviours is illustrated as procedural steps through the activity together with some textual descriptions in Fig. 3. 


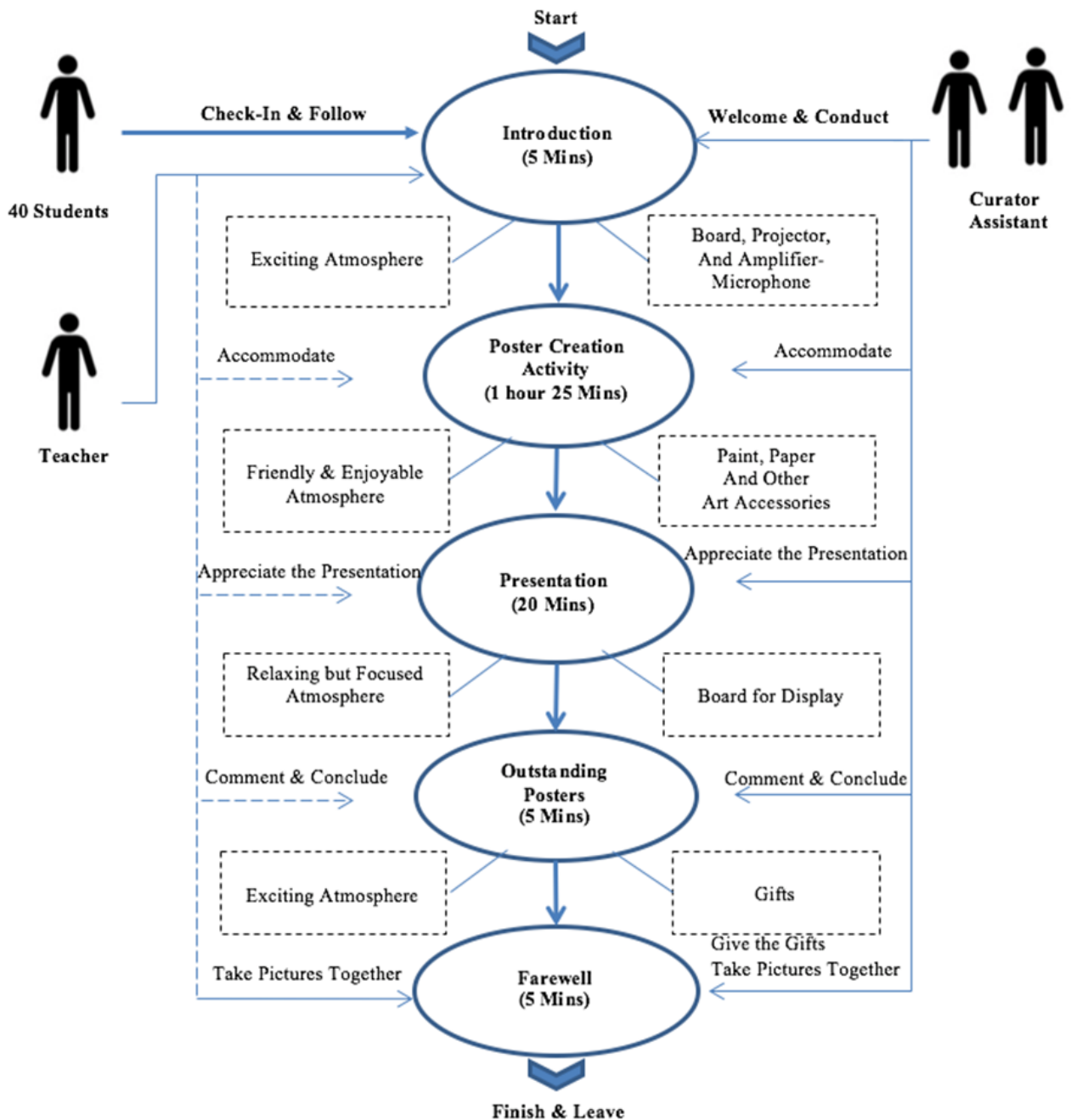

Figure 3: A diagram of the procedural steps of the "One day in the gallery" activity

\subsection{Area management for activities}

The areas in the gallery were divided and managed as areas for permanent exhibits and multipurpose areas. The total space of the multi-purpose areas was 4 times larger than that of the permanent exhibit areas. The multi-purpose areas might host an exhibit but it would not be permanently displayed. In general, the areas would be temporarily adapted for a special purpose then newly adapted for a subsequent purpose. An officer of the gallery gave the following statement.

"During summertime, a summer art practice or other activities will be organized at a multi-purpose area. No specific area is arranged for it. Everything depends on the situation at that time because, here, art exhibits are circulated in and out all the time; nevertheless, there will always be available areas for all activities." 


\subsection{Present limitations and expectations for the future (at the interview time)}

The external factor needed to be considered were whether arranging an activity in the intended area would worth the cost and whether the supporting materials could be conveniently acquired and reused, hence the processes and materials would be sustainable. The aspects to be considered were convenience, flexibility as well as time and labour saving, as the executive director said,

"Certainly, everything depends on the budget, but usually it is not an obstacle. More importantly is the suitability and worthiness of an activity in a situation. Furthermore, if all of the processes and materials can be reused, that will be excellent."

She also said,

“... I would like that the processes and materials will be reusable for other kinds of activities. They should be easy to set up and involve no complicated procedures because one of our limitations is that we have a small number of staff members," and "... if the area can be easily arranged by a small number of people, it will be very interesting. In a typical day, we are quite busy because we have to take care of many things at the same time."

\subsection{Results of the physical survey of the intended area in the existing environment}

The existing multi-purpose areas were of many forms and could be adapted for many functions conveniently. There were four types of space in and around the gallery (See the illustration in figure $4)$.

1. 'Open space' was the outer space of the building. This area has often been used to hold important ceremonies of art exhibitions. However, due to the hot weather, 34-38 degree Celsius, during the day, it is common for events to be held in the morning or in the evening.

2. 'Open space-roof covering': this area has been used quite often. Most activities held here have been fun activities on holidays such as on the National Children's Day. The weather in this area was still quite hot, so it was not suitable for an activity that requires concentration.

3. The 'semi-closed space' was a room with a glass wall. An activity in the room could be clearly observed and the people inside could also see things outside. However, since it was constructed with walls on all sides, it could be too hot and stuffy, so air-conditioning was necessary.

4. 'Closed space' is the fourth type of areas in the survey. This type of area was surrounded by white walls and had a 6-metre-high ceiling. There were also bright fluorescent lighting fixtures on the ceiling, convenient electrical outlets around the room, and high-capacity airconditioners to accommodate all kinds of activities.

To summarize, the last two types of area had a sufficient potential to be developed into an area for the 'One day in the gallery' activity, but the fourth type was more spacious; it could accommodate 40-50 people. Therefore, we chose an area of this type as the intended area for this activity and investigated its interior environment.

We also found that the furniture pieces in the intended area were not only multi-purposes but also easy to store and move. One hundred fifty to two hundred seats were available for any general uses. No audiovisual equipment such as speakers, amplifier, and projector were installed and permanently fixed to the room. 


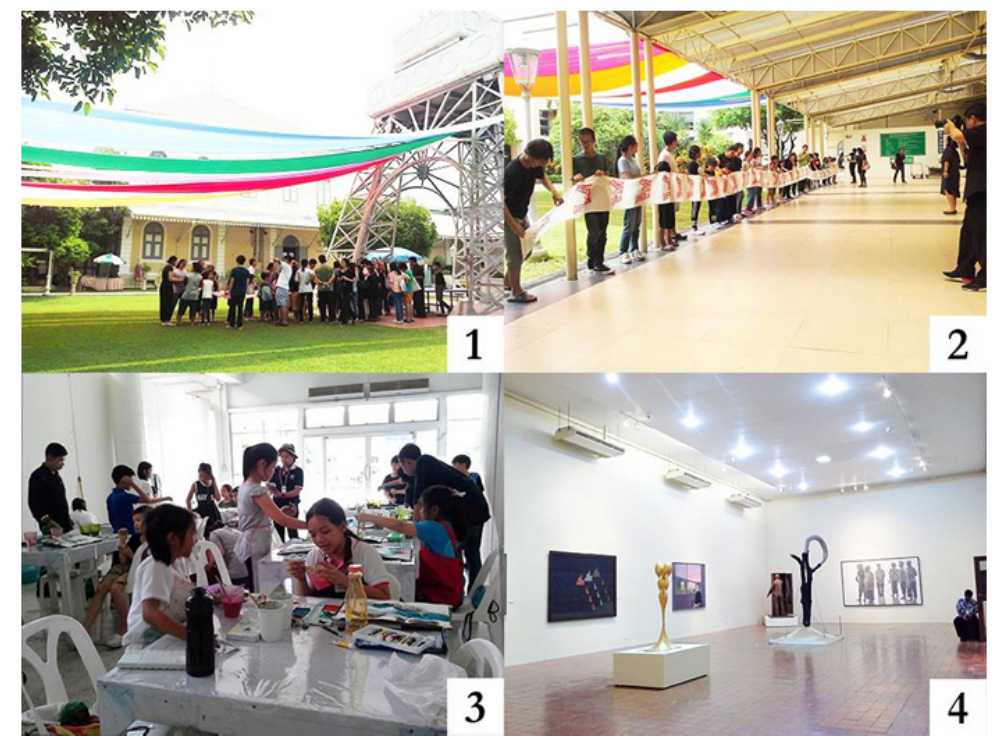

Figure 4: Forms of four multi-purpose areas in The National Gallery of Thailand Source: Author

\subsubsection{Quantitative results}

\subsection{User preferences}

From our perspective on the design of the area, we expected that the students would agree on the following statements about the interior environment. The high mean score of the students' responses to each statement proved that our expectation was valid.

- The art activity area should be well-decorated $(\bar{X}=4.41, \mathrm{SD}=0.74)$

- The temperature in the art activity area should be comfortable $(\bar{X}=4.47, S D=0.71)$

- The light in the art activity area should be sufficient for the purpose $(\bar{X}=4.10, S D=0.84)$

- The space in the art activity area should be sufficiently roomy $(\bar{X}=4.52, S D=0.73)$

- The art activity area should be able to accommodate a refreshment table $(\bar{X}=4.42, \mathrm{SD}=$ 0.85)

- The ambience of the art activity area should be amicable $(\bar{X}=4.35, \mathrm{SD}=0.80)$

- The atmosphere in the art activity area should be relaxing $(\bar{X}=4.53, \mathrm{SD}=0.68)$

- The pleasant atmosphere in the art activity area should stimulate a fun art activity $(\bar{X}=$ $4.48, \mathrm{SD}=0.72$ )

- Color lights and music excite an art activity $(\bar{X}=4.46, S D=0.74)$

\subsubsection{Preliminary designs}

Three preliminary designs were drawn up according to the results from 4.1 .1 and those from an analysis of interior design principles in design programming. The first part of the outcome of the design programming was 3 sets of environmental elements with the specifications shown in Table 1. The second part was three preliminary designs of the intended area: Design 1 that incorporated set $A$ of the environmental elements, Design 2 that incorporated set $A$ and set $B$, and Design 3 that incorporated all three sets, as listed in Table 2. A layout plan of Design 1, with the set of primary environmental elements, was drawn up. Three 3D perspectives of all 3 designs were produced by a computer program. 
Table 1 shows a list of specifications of environmental elements in set A, necessary primary elements, as well as those in Set B and $C$ which are different elements of positive stimuli. The details of all of these elements can be seen in the table.

Table 1: Sets of specifications for environmental elements used in the three designs

\begin{tabular}{|c|c|c|}
\hline Elements & Specifications & Authors \\
\hline Set $A$ & & \\
\hline $\begin{array}{ll}\text { (Newly arranged } & \text { primary } \\
\text { environmental elements } & \text { already } \\
\text { existed in the area) } & \end{array}$ & & \\
\hline Space & $\begin{array}{l}\text { Type } 4 \text { (closed space) } \\
(9.24 \times 12.63 \times 6.00 \text { Meters })\end{array}$ & $\begin{array}{l}\text { Zumthor, 2006; } \\
\text { Pallasmaa, 2014; } \\
\text { Mahmoud, } 2017\end{array}$ \\
\hline Furniture & $\begin{array}{l}8 \text { multi-purpose tables (5 persons } 11 \\
\text { group) } \\
45 \text { Chairs } \\
1 \text { table for curator } \\
1 \text { table for art accessories } \\
1 \text { table for beverage }\end{array}$ & (All 5 elements) \\
\hline Equipment & $\begin{array}{l}\text { Projector } \\
\text { Amplifiers-microphones }\end{array}$ & \\
\hline Air & Temperature at 24-25 Degree Celsius & \\
\hline Light & 380-400 Lux (Cool Tone \& Warm Tone) & \\
\hline $\begin{array}{l}\text { Set B } \\
\text { (Newly introduced elements of } \\
\text { positive stimuli) }\end{array}$ & & \\
\hline $\begin{array}{l}\text { Wall decoration with pieces of } \\
\text { circular color paper }\end{array}$ & $\begin{array}{l}\text { Blue \& Orange circles of various sizes } \\
\text { (blue, light blue, very light blue, and } \\
\text { orange }\end{array}$ & $\begin{array}{l}\text { Aronoff et al., 1988; } \\
\text { Wang and Zhang, } \\
2016\end{array}$ \\
\hline \multicolumn{3}{|l|}{$\begin{array}{l}\text { Set C } \\
\text { (More newly introduced elements } \\
\text { of positive stimuli) }\end{array}$} \\
\hline Colour lighting & $\begin{array}{l}\text { Remotely-controlled LED Multi-colour } \\
\text { lights (especially blue and green) that } \\
\text { changed with the flow of the activity }\end{array}$ & Abbas, 2006 \\
\hline Background Music & $\begin{array}{l}\text { Happy and inspiration music that set the } \\
\text { mood of the flow of the activity }\end{array}$ & Herrmann, 2009 \\
\hline
\end{tabular}

Table 2: The three designs created in this study

\begin{tabular}{|l|c|c|c|}
\hline Design: Level of Stimuli & Set A & Set B & Set C \\
\hline Design 1: Low & & - & - \\
\hline Design 2: Moderate & & & - \\
\hline Design 3: High & & & \\
\hline
\end{tabular}

Fig. 5 displays the layout plan of the area with Set A of environmental elements. Fig. 6 illustrates 
the 3D perspectives of the 3 designs: Design 1 with Set $A$, Design 2 with Sets $A$ and $B$, and Design 3 with Sets $A, B$, and $C$. Design 1 contained only primary environmental elements which were low stimuli. Design 2 added some positive stimuli elements in Set B, and Design 3 added elements in Set $C$ to provide a higher degree of positive stimuli, the highest in this study.

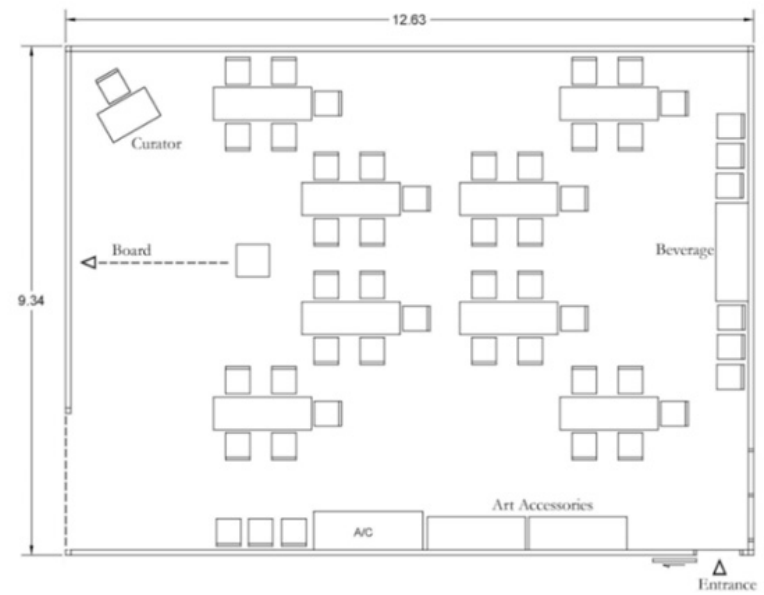

Figure 5: Layout plan of primary environment

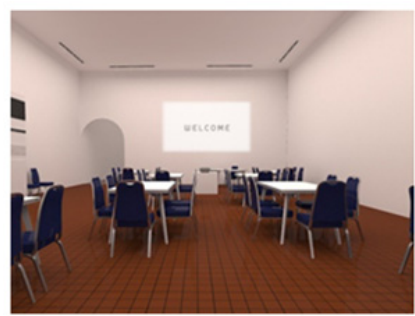

Design 1

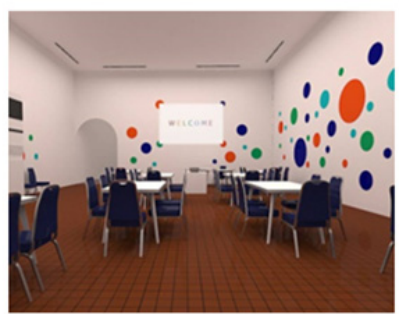

Design 2

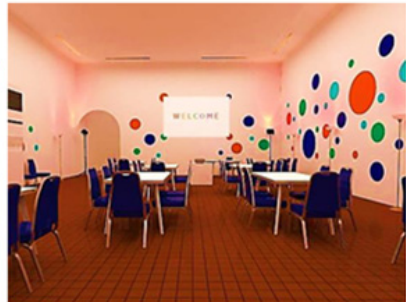

Design 3

Figure 6: 3D perspectives of the three designs

\subsection{Assessment of preliminary designs}

Assessment scores, means and standard deviations of 5 aspects, on the designs in terms of space quality by 10 design experts show that Design 1 was suitable at a moderate level $(\bar{X}=3.10$, SD $=$ $0.1)$, while Design 2 and 3 were suitable at a very high level: $(\bar{X}=4.51$ SD $=0.14)$ and $(\bar{X}=4.59, S D$ $=0.19$ ), respectively, as listed in Table 3 .

Table 3: Means and standard deviations of scores on 5 aspects of the three preliminary designs.

\begin{tabular}{|c|c|c|c|c|c|c|}
\hline \multirow{2}{*}{ Item } & \multicolumn{2}{|c|}{ Design 1} & \multicolumn{2}{|c|}{ Design 2} & \multicolumn{2}{|c|}{ Design 3} \\
\hline & $\overline{\bar{X}}$ & SD & $\overline{\bar{X}}$ & SD & $\bar{X}$ & SD \\
\hline 1. Physical & 4.35 & 0.46 & 4.35 & 0.46 & 4.35 & 0.46 \\
\hline 2. Artefact & 4.26 & 0.41 & 4.26 & 0.41 & 4.26 & 0.41 \\
\hline 3. Trait & 2.41 & 0.53 & 4.70 & 0.26 & 4.78 & 0.18 \\
\hline 4. Behaviour & 2.21 & 0.43 & 4.43 & 0.32 & 4.53 & 0.24 \\
\hline 5. Social Climate & 2.25 & 0.72 & 4.80 & 0.35 & 4.80 & 0.18 \\
\hline Total & 3.10 & 0.16 & 4.51 & 0.14 & 4.59 & 0.19 \\
\hline Suitability & \multicolumn{2}{|c|}{ Moderate } & & & \multicolumn{2}{|c|}{ Very High } \\
\hline
\end{tabular}




\section{Discussion and Conclusion}

The main outcomes of this study are two highly suitable designs-Design 2 and 3-of the interior elements of an intended area for an art activity in the National Gallery of Thailand. Design 2 and 3 were sets of positive stimuli based on the psychological principles of environment perceptionDesign 2 was a set of moderate positive stimuli that rendered the space pleasant and fun, while Design 3 was a set of high positive stimuli that rendered the space excited but not so much as to be unpleasant. On the other hand, Design 1 was a set of primary interior environmental elements with a lower level of stimuli than the other two which achieved moderate assessment scores signifying that the design provided positive perceptions but the ambience was not very active due to less positive stimuli from the extra elements. These outcomes are in good agreement with theories on environmental psychology, particularly with a result on human emotional states from perception of stimuli in the environment reported by Russell (1980) that human beings are highly satisfied with their perception of moderate stimuli in the environment. They are also supported by a result from a study by Miwa and Hanyu (2006) that a room that is well-decorated and illuminated with a proper intensity of light provides a positive perception to individuals. This is not surprising because our designs were based on a suggestion by Zumthor (2006), Pallasmaa (2014), and Mahmoud (2017) that a good interior environmental design can be achieved by combining the right elements to create an intended atmosphere as well as functional and aesthetic design principles upheld by Rengel (2016). Moreover, the quality of the designs was judged to be good according to the evaluation criteria of Craik (1971).

To conclude, designs for an area in the National Gallery of Thailand intended for an art activity called "One day in the Gallery" were drawn up and assessed. Two designs-Design 2 and 3which contained sets of interior environmental elements of positive stimuli at moderate and high level were judged to be most suitable. Design 3 got the highest average score but still in the same expected range, so either design can be used depending on the level of intended convenience or a desire to change the atmosphere. The reason behind this conclusion is that both designs shared a same set of primary interior environmental elements but Design 3 added more elements of positive stimuli to this basic set of primary elements than Design 2 did. Therefore, Design 3 required more budget to construct. Both designs were fully evaluated to be able to accomplish the objective for the intended area as a focused but enjoyable area for an art-learning activity. Moreover, the designs and the survey results also reflected that the intact environment in the gallery, in Design 1, had already had an adequate number of interior environmental elements and equipment. It only lacked some elements of positive stimuli. We proposed the chosen designs with sufficient levels of positive stimuli so that the ambience of the intended area and art activity would be enthusiastic and pleasurable.

\section{References}

Abbas, N. (2006). The Psychological and Physiological Effects of Light and Colour on Space Users, [Online] Available: https://researchbank.rmit.edu.au/eserv/rmit:6262/Abbas.pdf (March 11, 2017)

Aronoff, J., Barclay, A. M., \& Stevenson, L. A. (1988). The recognition of threatening facial stimuli. Journal of Personality and Social Psychology, 54, 647-655.

Augustin, S., \& Coleman, C. (2012). The Designer's guide to doing research: applying knowledge to inform design. New Jersey: John Wiley \& Sons.

Bar, M., \& Neta, M. (2006). Humans prefer curved visual objects. Psychological Science, 17(8), 645-648.

Carp, F. M., \& Carp, A. (1982). Perceived environmental quality of neighborhoods: Development of assessment scales and their relation to age and gender. Journal of Environmental Psychology, 2, 295-312.

Craik, K. H. (1971). The assessment of places. In P. McReynolds (ed.), Advances in Psychological Assessment. (Vol. 2, pp. 40-62). Palo Alto, CA: Science and Behavior Books.

Craik, K. H., \& Zube, E. (1976). Perceiving environmental quality: Research and applications. New York: Plenum.

Denscombe, M. (2010). The Good Research Guide for small-scale social research projects. (4th ed.). England: McGraw-Hill

Foley, M., \& McPherson, G. (2000). Museum as Leisure. International. Journal of Heritage Studies, 6(2), 161174. 
Glesne, C. (2012), The Campus Art Museum: A Qualitative Study. [Online] Available: http://www.kressfoundation.org/research/campus art museum (April 3, 2017)

Hardiman, M. (2012) Informing Pedagogy Through the Brain-Targeted Teaching Model. Journal of Microbiology \& Biology Education, 13(1), 11-16.

Herrmann, F. (2009). The Effect of Background Music in an Educational Setting. [Online] Available: https://frederickherrmann.files.wordpress.com/2009/02/background music paper.pdf_(April 3, 2017)

Hershberger, R. G. (1999). Architectural programming and predesign manager. New York: McGraw- Hill.

Karavidas, C. (2017). Environmental Design vs. Interior Design. [Online] Available: https://clearph.com/environmental-design-vs-interior-design/(August 7, 2017)

Lin. Y.-N. (2013). A study on visitor's motivation at the Taipei fine arts museum. Journal of Museum \& Culture, $6,167-189$.

Mahmoud, H.T.H. (2017). Interior Architectural Elements That Affect Human Psychology and Behavior.1(1). [Online] Available: https://ssrn.com/abstract=3055621 (April 2, 2017)

Miwa, Y., \& Hanyu, K. (2006). The effects of interior design on communication and impressions of a counselor in a counseling room. Environment and behavior, 38(4), 484-502.

Miller, A., \& Cunningham, K. (2011). Classroom Environment. [Online] Available: https://www.ortingschools.org/cms/lib03/WA01919463/Centricity/domain/326/purp ose/research/Classroom\%20Environment\%20article.pdf (April 17, 2017)

Mukdamanee, W. (2012). Thai Youth Encyclopedia. vol. 77(2), [Online] Available: http://kanchanapisek.or.th/kp6/sub/book/book.php?book=37\&chap=2\&page=chap2. htm (February 10, 2017)

National Gallery Singapore, (2018). School Programmes. [Online] Available: https:// www.nationalgallery.sg/discover-learn/schools (August 19, 2018)

Newcastle Art Gallery, (2018). Idea for Classroom Learning. [Online] Available: https://www.nag.org.au/Engage/Learning-Programs/Education-Resources/ldeas-for- classroom-learning (August 19, 2018)

Pallasmaa, J. (2014). Space, place and atmosphere: Emotion and peripheral perception in architectural experience. Lebenswelt: Aesthetics and Philosophy of Experience, 4, 230-245.

Palmer, M. A. (1981). The Architect's Guide to Facility Programming. New York: McGraw-Hill.

Renjel, R. J. (2016). Interior Plan: Concepts and Exercise. (2nd ed.). New York: Fairchild Books

Russell, J. A. (1980) A circumplex model of affect. Journal of Personality and Social Psychology, 39(6), 11611178.

Sigman, J. K. (2005). Using Background Music in Classroom Effectively Enhance Concentration Within the Learning Environment. [Online] Available: https://etd.ohiolink.edu/rws_etd/document/get /marietta1112128560/inline (April 11, 2017)

Testado, J. (2018). LMN Architects begins renovation on Seattle's Asian Art Museum. [Online] Available: https://archinect.com/news/bustler/6430/lmn-architects-begins-renovation- on-seattle-s-asian-art-museum (April 15, 2018)

Vischer. J.C., \& Fischer. G.-N. (2005). User evaluation of the work environment: A diagnostic approach. Le travail humain, 68(1), 73-96.

Wang, Y., \& Zhang, Q. (2016). Affective priming by simple geometric shapes: Evidence from event-related brain potentials. Frontiers in Psychology, 7, 917.

Wright, A. (2018). Colour affect: Psychological Properties Of Colours. [Online] Available: http://www.colouraffects.co.uk/psychological-properties-of-colours (April 9, 2017)

Zumthor, P. (2006). Atmosphere: Architectural environments, Surrounding objects. Basel: Birkhäuser. 